\title{
Effects of ILeVO Seed Treatment on Heterodera glycines Reproduction and Soybean Yield in Small-Plot and Strip-Trial Experiments in lowa
}

\author{
Kaitlyn M. Bissonnette, ${ }^{1}$ Christopher C. Marett, ${ }^{1}$ Mark P. Mullaney ${ }^{1}$, Gregory D. Gebhart ${ }^{1}$, Peter M. Kyveryga, ${ }^{2}$ Tristan A. Mueller $^{3}$, \\ and Gregory L. Tylka ${ }^{1, \dagger}$ \\ ${ }^{1}$ Department of Plant Pathology and Microbiology, Iowa State University, Ames, IA 50011 \\ ${ }^{2}$ Iowa Soybean Association Research-Analytics, Ankeny, IA 50023 \\ ${ }^{3}$ Formerly, Iowa Soybean Association Research-On-Farm Network, Ankeny, IA 50023
}

\begin{abstract}
ILeVO (fluopyram) is a fungicide seed treatment for soybean sudden death syndrome (SDS) that also has nematicidal activity. ILeVO is sold with a base of insecticide Poncho (clothianidin), nematode-protectant VOTiVO (Bacillus firmus), and Acceleron fungicides (metalaxyl, fluxapyroxad, and pyraclostrobin). Yield and reproduction of the soybean cyst nematode (SCN) (Heterodera glycines) on soybean plants grown from seed treated with ILeVO plus the base were compared with those treated with only the base in 27 small-plot experiments and 12 strip-trial experiments across Iowa from 2015 to 2017. To increase the likelihood that yield results were related to effects on SCN, data were used only from 26 small-plot experiments and 12 strip trials in which symptoms of SDS were low or nonexistent. An SCN reproductive factor (RF) was cal-

reduced SCN RF by $50 \%$ in one strip-trial experiment and by 36 to $60 \%$ in four small-plot experiments but yields were not increased by ILeVO in any of those five experiments. Soybean yields were 2.8 to 3.7 bushels/ acre (bu/ac) (188.3 to $248.8 \mathrm{~kg} / \mathrm{ha}$ ) greater with ILeVO in three smallplot experiments but SCN RF was not reduced in those experiments. Also, yield was $1.9 \mathrm{bu} / \mathrm{ac}(127.8 \mathrm{~kg} / \mathrm{ha})$ greater with ILeVO in one strip-trial experiment in 2016 but SCN samples were not collected at harvest from the study to assess the possible effects of ILeVO on SCN reproduction. When strip-trial data from 2015 and 2016 were combined, there was a small but significant $0.8 \mathrm{bu} / \mathrm{ac}(52.2 \mathrm{~kg} / \mathrm{ha})$ yield increase with ILeVO. Overall, the effects of ILeVO on SCN reproduction and soybean yield were variable in these field studies.
\end{abstract} culated for each experimental unit by dividing the SCN population density at harvest by the population density at planting. ILeVO significantly
Keywords: chemical, disease management, field crops, nematodes
The soybean cyst nematode ( $\mathrm{SCN}$ ) (Heterodera glycines) is the most damaging pest of soybean (Glycine max) in North America (Allen et al. 2017), and it is widespread throughout the soybeangrowing regions of the United States and Canada (Tylka and Marett 2017). This pest was estimated to have caused yield suppression of more than 108 million bushels or 2.94 million metric tons per year in the United States from 2010 to 2014, which equates to more than US\$1 billion in losses annually (Allen et al. 2017).

For decades, SCN was managed by growing resistant soybean cultivars in rotation with nonhost crops such as corn (Zea mays). Nematode-protectant seed treatments were introduced in the 2000s, providing additional options for managing SCN. Among the nematode-protectant seed treatments currently available is ILeVO (fluopyram; BASF, Florham Park, NJ, U.S.A.). Fluopyram is a succinate dehydrogenase inhibitor, a class of fungicides known to inhibit mitochondrial respiration in fungi. This fungicide also has been found to have nematicidal effects on the southern root-knot nematode (Meloidogyne incognita) and the reniform nematode (Rotylenchulus reniformis) (Faske and Hurd 2015; Jackson et al. 2015; Jones et al. 2017). In these studies, fluopyram reduced the ability of the

Current address of K. M. Bissonnette: Division of Plant Sciences, University of Missouri, Columbia, MO 65211.

Current address of T. A. Mueller: BioConsortia, Davis, CA 95618.

${ }^{\dagger}$ Corresponding author: G. L. Tylka; gltylka@iastate.edu

Funding: This work was funded, in part, by the soybean checkoff through the Iowa Soybean Association and by the Iowa Agriculture and Home Economics Experiment Station, projects 5309 and 5490.

The author(s) declare no conflict of interest.

Accepted for publication 4 May 2020.

(C) 2020 The American Phytopathological Society aforementioned nematodes to penetrate roots and decreased the number of females in the roots of the affected crops.

Fluopyram was first registered in 2014 for use with soybean as a seed treatment for the management of sudden death syndrome (SDS) (caused by Fusarium virguliforme). It is known that SDS symptoms occur earlier in the season and become more severe in fields infested with SCN as compared with fields not infested with the nematode (Hirrel 1987; McLean and Lawrence 1993; Melgar et al. 1994; Roy et al. 2000; Westphal et al. 2014; Xing and Westphal 2006). A seed treatment for SDS that also has nematicidal action could reduce both the population density of SCN in the soil and diminish the impacts of SDS and SCN on soybean yield. Ideally, to study the effectiveness of the seed treatment ILeVO for SCN management, experiments should be conducted in fields with little or no SDS to minimize confounding effects. Kandel et al. (2016b) advise that SDS disease index should be low (below 10) for treatment effects on yield to be related to SCN management.

ILeVO has been shown to reduce hatching of SCN juveniles from eggs, the movement of those juveniles, and the ability of juveniles to penetrate soybean roots in experiments conducted in controlled environments (Beeman and Tylka 2018; Beeman et al. 2019). However, to our knowledge, results of experiments conducted over multiple years and a wide range of geographical locations assessing the impacts of the ILeVO seed treatment on SCN population density and soybean yield in fields with SDS index levels below 10 have not been published. The purpose of this study was to determine the effectiveness of ILeVO seed treatment in reducing SCN reproduction and increasing soybean yield in small-plot and strip-trial experiments throughout Iowa.

\section{Materials and Methods}

Experiment designs. From 2015 to 2017, nine small-plot experiments were conducted each year, one in each of the nine cropreporting districts of Iowa (Fig. 1A), with each experiment being located in a different field or different area of a field each year. In addition, 12 strip-trial experiments were conducted, 5 in 2015 and 7 in 2016, across the state of Iowa (Fig. 1B). Both types of experiments 
were conducted in fields in which corn (Z. mays) was grown the previous year, and glyphosate as well as conventional pre- and postemergence herbicides were used for weed control. Two seed treatments were compared in all experiments: the base treatment of Poncho/ VOTiVO (clothianidin at $0.13 \mathrm{mg} / \mathrm{seed}$ and Bacillus firmus strain I1582 at $5 \times 10^{6}$ spores/seed; BASF) and Acceleron F (0.0405 mg of pyraclostrobin, $0.081 \mathrm{mg}$ of metalaxyl, and $0.0243 \mathrm{mg}$ of fluxapyroxad per seed; Bayer Crop Science, St. Louis, MO, U.S.A.) and the base treatment plus ILeVO (fluopyram at $0.15 \mathrm{mg} / \mathrm{seed}$; BASF). The seed treatments were applied by the manufacturer to single batches of single lots of seed each year so that the seed used in the small-plot and striptrial experiments were the same. Soybean cultivar AG2031 (Bayer Crop Science) was used for all small-plot and strip-trial experiments in 2015, in the three small-plot experiments in the northern cropping districts in 2016 and 2017, and in four strip-trial experiments in 2016. The soybean cultivar AG3231 was used at the remaining six small-plot experiments (the central three and southern three cropping districts) in 2016 and in 2017 as well as in three strip-trial experiments in 2016. Both soybean cultivars were resistant to SCN and contained the PI 88788 source of resistance.

The small-plot experiments were planted, harvested, and maintained by Iowa State University personnel, whereas the strip-trial experiments were planted, maintained, and harvested by farmers cooperating with the Iowa Soybean Association On-Farm Network. The small-plot experiments were planted in May of each year using a four-row Almaco CTS planter. Each small plot was 17 feet $(5.18 \mathrm{~m})$ long and four rows wide with a 30 -inch $(0.76-\mathrm{m})$ row spacing. Treatments were arranged in a randomized complete block design with 12

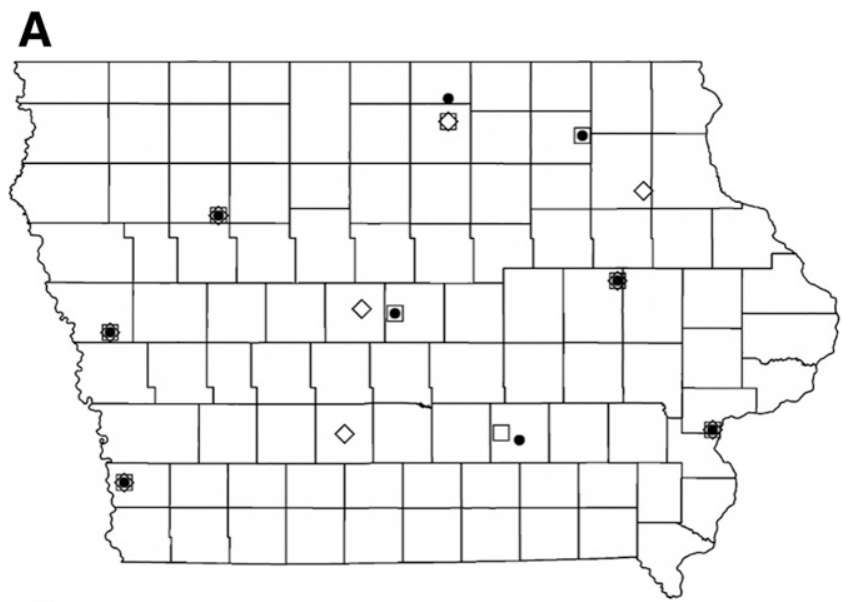

B

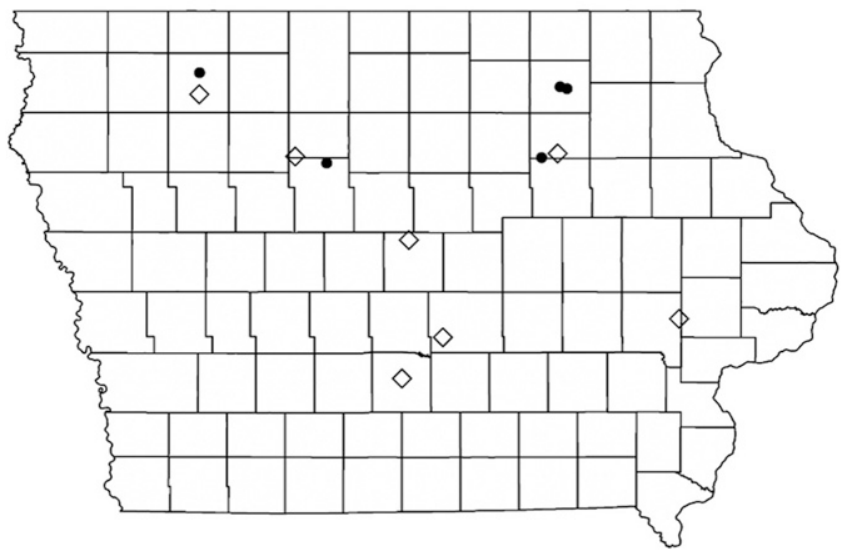

Fig. 1. Locations of the A, 27 small-plot experiments and $\mathbf{B}, 12$ replicated strip trials across lowa in each year of the study. Solid circles represent sites used in 2015, diamonds represent sites used in 2016, and squares represent sites used in 2017; multiple symbols are combined for experiments conducted at the same farm for 2 or 3 years. replications per treatment. For the strip-trial experiments, fieldlength strips were planted for each treatment ranging from 820 to 1,600 feet long ( 250 to $488 \mathrm{~m}$ long), with each treatment replicated four or more times in each field. The plots in each small-plot and strip-trial experiment were observed for foliar symptoms of SDS, and an SDS foliar disease index value was estimated for each experiment. SDS incidence (percentage of plot or scouting area affected by SDS) and SDS severity (percent interveinal necrosis and chlorosis or leaf drop of the leaves of affected plants) were estimated for each plot and strip. These values were then used to calculate the SDS disease index of each experiment, where SDS disease index $(0$ to 100) $=$ (SDS incidence $\times$ SDS severity)/9 (Njiti et al. 1998). In October of each year, the center two rows of each plot in the small-plot experiments were harvested with an Almaco SPC-20 plot combine and yield was calculated. Strip-trial experiments were harvested by cooperating farmers with their own combines equipped with GPSreferenced yield monitors.

Quantifying SCN population densities. SCN egg population densities were determined for each small plot and for most strips in

Table 1. Initial soybean cyst nematode $(\mathrm{SCN})$ population density in each small-plot field experiment from 2015 to 2017 , HG type test results of the SCN population in each field, and percent reproduction on PI 88788

\begin{tabular}{|c|c|c|c|}
\hline Year, location & $\mathbf{P}_{\mathbf{i}}^{\mathbf{a}}$ & $\begin{array}{l}\text { SCN HG } \\
\text { type }^{b}\end{array}$ & $\begin{array}{c}\text { Reproduction on PI } 88788 \\
(\%)^{c}\end{array}$ \\
\hline \multicolumn{4}{|l|}{2015} \\
\hline Northwest & 4,894 & 2.5 .7 & 22 \\
\hline Northcentral & 11,992 & 2.7 & 19 \\
\hline Northeast & 1,763 & 2.5 .7 & 29 \\
\hline West Central & 769 & 2.5 .7 & 33 \\
\hline Central & 5,016 & 2.5 .7 & 32 \\
\hline East Central & 760 & 2.7 & 14 \\
\hline Southwest & 1,902 & 2.5 .7 & 16 \\
\hline Southcentral $^{\mathrm{d}}$ & 6,208 & 2.5 .7 & 38 \\
\hline Southeast & 6,082 & 2.5 .7 & 22 \\
\hline \multicolumn{4}{|l|}{2016} \\
\hline Northwest & 732 & 1.2.5.7 & 41 \\
\hline Northcentral & 4,060 & 2.5 .7 & 26 \\
\hline Northeast & 1,097 & 2.5 .7 & 40 \\
\hline West Central & 2,298 & 2.5 .7 & 20 \\
\hline Central & 300 & 1.2.5.7 & 55 \\
\hline East Central & 242 & 2.5 .7 & 47 \\
\hline Southwest & 1,850 & 1.2.5.7 & 37 \\
\hline Southcentral & 322 & 2.7 & 15 \\
\hline Southeast & 3,500 & 2.5 .7 & 66 \\
\hline \multicolumn{4}{|l|}{2017} \\
\hline Northwest & 862 & $2-$ & 30 \\
\hline Northcentral & 621 & $2-$ & 18 \\
\hline Northeast & 2,087 & $2-$ & 35 \\
\hline West Central & 1,039 & $2-$ & 37 \\
\hline Central & 1,828 & $2-$ & 33 \\
\hline East Central & 941 & $2-$ & 33 \\
\hline Southwest & 626 & $1.2-$ & 59 \\
\hline Southcentral & 783 & $1.2-$ & 43 \\
\hline Southeast & 969 & $2-$ & 56 \\
\hline
\end{tabular}

${ }^{a} \mathrm{P}_{\mathrm{i}}=$ initial soybean cyst nematode $(\mathrm{SCN})$ population density reported as the number of SCN eggs per $100 \mathrm{~cm}^{3}$ of soil.

b Numbers in the SCN HG type test designations indicate on which of the seven HG type indicator lines used in the test there was $>10 \%$ SCN reproduction; namely, Peking (number 1), PI 88788 (number 2), PI 209332 (number 5), or PI 548316 (number 7). The - sign after the HG type designations for 2017 indicate that only Peking (number 1), PI 88788 (number 2), and PI 437654 (number 4) were included as indicator lines for the HG type test.

c Percent reproduction on PI 88788 was calculated as the number of females present after 30 days on roots of pure PI 88788 divided by the number of females on the susceptible check line Lee after 30 days, then multiplied by 100 .

d Sudden death syndrome disease index values were $>10$ at the Southcentral location in 2015. Therefore, yield and SCN reproductive factor data generated at this location were removed from further analyses. 
every year from soil samples collected at or near the time of planting (initial population density $\left[\mathrm{P}_{\mathrm{i}}\right]$ ) and again following harvest (final population density $\left[\mathrm{P}_{\mathrm{f}}\right]$ ). For the small-plot experiments, 10 soil cores, 1 in. $(2.5 \mathrm{~cm})$ in diameter and 8 in. $(20 \mathrm{~cm})$ deep, were collected in a zig-zag pattern from either side of the center two rows of each plot, and the cores were thoroughly mixed. In the strip-trial experiments, 20 similarly sized soil cores were collected in midJune and again after harvest around arbitrarily selected, paired sampling locations within pairs of strips, as described by Bissonnette et al. (2018). For each sample, the 20 soil cores were combined and mixed to represent each sampling point. SCN cysts were extracted from each soil sample on a $250-\mu \mathrm{m}$-pore sieve using a modified wet-sieving and decanting method (Gerdemann 1955). SCN eggs then were extracted from the cysts with a motorized rubber stopper (Faghihi and Ferris 2000), collected on a 25- $\mu \mathrm{m}$-pore sieve, stained (Niblack et al. 1993), and counted. A reproductive factor (RF) for SCN was calculated for each plot and strip by dividing the $\mathrm{P}_{\mathrm{f}}$ by the $\mathrm{P}_{\mathrm{i}}$, which is a ratio that measures the change in the number of SCN eggs per volume of soil over an entire growing season. If $\mathrm{RF}=1$, there was no change in the SCN population density from the beginning to the end of the season; if $\mathrm{RF}<1$, SCN egg population densities decreased through the season; and if RF $>1$, SCN population densities increased throughout the season. For the Warren County strip trial in 2016, soil samples were not collected after harvest; therefore, an SCN RF was not calculated for that location.

An HG type test (Niblack et al. 2002) was conducted on the SCN population in each field of the small-plot experiments (Table 1). Initial SCN population density, percent reproduction or female index of the SCN populations on PI 88788, and the HG type of the SCN populations for the 27 small-plot experiments are shown in Table 1.

Data analysis. The data collected from the small-plot experiments were analyzed separately from the data collected in the strip trials. To analyze the effects of seed treatment on SCN RF and soybean yield in the small-plot experiments, year, location (nested in year), and replication (nested in year and location) were considered random effects and the seed treatment was a fixed effect. The data from the smallplot experiments also were combined into three regions (fixed effect) for further analysis: the Northern region, comprising experiments in the Northwest, Northcentral, and Northeast cropping districts; the Central region, comprising experiments in the West Central,

Table 2. Mean reproduction of Heterodera glycines and mean soybean yield in the small-plot experiments for plots treated with and without ILeVO and the difference between treatment means for each location in each year ${ }^{\mathrm{a}}$

\begin{tabular}{|c|c|c|c|c|c|c|}
\hline \multirow[b]{2}{*}{ Year, location } & \multicolumn{3}{|c|}{ SCN reproductive factor ${ }^{b}$} & \multicolumn{3}{|c|}{ Yield (bushels/acre) } \\
\hline & ILeVO + base & Base & Difference $^{c}$ & ILeVO + base & Base & Difference $^{c}$ \\
\hline \multicolumn{7}{|l|}{2015} \\
\hline Northwest & 1.5 & 1.6 & -0.1 & 76.9 & 76.2 & 0.7 \\
\hline Northcentral & 0.4 & 0.5 & -0.1 & 72.5 & 72.6 & -0.1 \\
\hline Northeast & 1.9 & 1.4 & 0.5 & 56.9 & 57.4 & -0.5 \\
\hline West Central & 1.6 & 1.2 & 0.4 & 80.8 & 80.2 & 0.6 \\
\hline Central & 0.7 & 0.6 & 0.1 & 59.7 & 59.1 & 0.6 \\
\hline East Central & 2.0 & 4.4 & $-2.4^{*}$ & 71.5 & 71 & 0.5 \\
\hline Southwest & 5.1 & 3.4 & 1.7 & 70.7 & 70.7 & 0 \\
\hline Southcentral $^{\mathrm{d}}$ & 0.5 & 0.9 & -0.4 & 58.0 & 57.5 & 0.5 \\
\hline Southeast & 1.3 & 1.5 & -0.2 & 46.4 & 47.8 & -1.4 \\
\hline All locations & 1.8 & 1.8 & 0 & 66.9 & 66.9 & 0 \\
\hline \multicolumn{7}{|l|}{2016} \\
\hline Northwest & 15.0 & 22.4 & -7.4 & 83.4 & 79.7 & $3.7 *$ \\
\hline Northcentral & 1.4 & 1.3 & 0.1 & 81.3 & 80.2 & 1.1 \\
\hline Northeast & 2.0 & 3.7 & -1.7 & 77.1 & 74.4 & 2.7 \\
\hline West Central & 3.7 & 3.7 & 0 & 73 & 74.3 & -1.3 \\
\hline Central & 14.1 & 8.7 & 5.4 & 76.5 & 75.9 & 0.6 \\
\hline East Central & 4.7 & 5.1 & -0.4 & 75.5 & 75.2 & 0.3 \\
\hline Southwest & 2.1 & 2.0 & 0.1 & 71.6 & 71.6 & 0 \\
\hline Southcentral & 0.6 & 1.5 & $-0.9^{*}$ & 80.2 & 80.1 & 0.1 \\
\hline Southeast & 0.3 & 0.3 & 0 & 42.9 & 45.6 & -2.7 \\
\hline All locations & 4.9 & 5.4 & -0.5 & 73.5 & 73.0 & 0.5 \\
\hline \multicolumn{7}{|l|}{2017} \\
\hline Northwest & 33.0 & 36.3 & -3.3 & 59.0 & 60.4 & -1.4 \\
\hline Northcentral & 2.1 & 1.9 & 0.2 & 71.2 & 71.0 & 0.2 \\
\hline Northeast & 0.6 & 1.0 & -0.4 & 58.8 & 57.6 & 1.2 \\
\hline West Central & 1.7 & 3.2 & $-1.6^{*}$ & 86.5 & 86.8 & -0.3 \\
\hline Central & 0.9 & 1.4 & $-0.5^{*}$ & 72.8 & 73.8 & -1 \\
\hline East Central & 1.5 & 2.2 & -0.7 & 69.3 & 68.8 & 0.5 \\
\hline Southwest & 55.7 & 60.1 & -4.4 & 76.1 & 76.6 & -0.5 \\
\hline Southcentral & 9.3 & 4.3 & $5.0^{*}$ & 60.0 & 57.1 & $2.9 *$ \\
\hline Southeast & 4.1 & 6.0 & -1.9 & 73.2 & 70.4 & $2.8^{*}$ \\
\hline All locations & 12.1 & 12.9 & -0.8 & 70.1 & 69.8 & 0.3 \\
\hline \multicolumn{7}{|l|}{ All years } \\
\hline All locations ${ }^{\mathrm{d}}$ & 6.63 & 7.14 & -0.51 & 69.7 & 69.4 & 0.3 \\
\hline
\end{tabular}

${ }^{a}$ Statistical differences are reported and significance was determined at $P=0.10$. Data from all locations were pooled by year and over all years. Locations were unique in each year and, therefore, the data were not pooled over all years by location.

${ }^{\mathrm{b}}$ Reproductive factor was calculated by dividing the number of soybean cyst nematode $(\mathrm{SCN})$ eggs in each plot at harvest $\left(\mathrm{P}_{\mathrm{f}}\right)$ by the number in each plot at planting $\left(\mathrm{P}_{\mathrm{i}}\right)$.

${ }^{c}$ Difference was calculated by subtracting the mean SCN reproductive factor or mean yield for the Poncho/VOTiVO + Acceleron F treatment (base) from the Poncho/VOTiVO + Acceleron F + ILeVO treatment (ILeVO + base). Asterisks $(*)$ indicate that the difference between treatments was statistically significant $(P \leq 0.10)$.

${ }^{\mathrm{d}}$ Due to sudden death syndrome disease index values $>10$, yield and reproductive factor of this small-plot experiment were not used in the overall summary for 2015 and across all years. 
Central, and East Central cropping districts; and the Southern region, comprising experiments in the Southwest, Southcentral, and Southeast cropping districts. SCN RF and soybean yield data were analyzed by individual experiment, with experiments pooled by region, with experiments pooled by year, and with all experiments pooled over all years. Random effects were estimated using best linear unbiased predictors, and significant differences were determined using $P=0.10$. All data analyses for the small-plot experiments were conducted in SAS statistical software (SAS Inc., Rockville, MD, U.S.A.) using the mixed-model procedure (PROC MIXED).

Data from the strip-trials also were analyzed using the mixedeffects model framework, with random effects of year and replications nested within locations and the fixed effect of the seed treatments. To better facilitate comparisons across different environments, absolute yield differences were expressed as percent yield change with the addition of ILeVO. The $90 \%$ confidence intervals for mean yield change at individual experiments and across all strip-trial experiments were calculated using a hierarchical model framework with Bayesian analyses (Laurent et al. 2019). All calculations were performed using lme4 and MCMCglmm (Hadfield 2010) packages in the RStudio (RStudio Team 2015).

Yield and RF data from one small-plot experiment in 2015 in Southcentral Iowa (Table 2) and two strip-trial experiments in 2016 in Humboldt County and Johnson County (Table 3) were excluded from all data analyses because the SDS disease index in those experiments was $>10$.

\section{Results}

Effects of ILeVO on changes in SCN population densities. The addition of ILeVO to the base seed treatment did not consistently result in significant reductions in SCN reproduction over the season in either the small-plot or strip-trial experiments. A significant reduction in RF was observed in only four small-plot experiments: East Central in $2015(P=0.07)$, Southcentral in $2016(P=0.05)$, West Central in $2017(P=0.04)$, and Central in $2017(P=0.096)$ (Table 2). In the 2015 East Central experiment, there was nearly a two-and-a-half-fold decrease in SCN reproduction in plots grown from seed treated with ILeVO $(\mathrm{RF}=2.0)$ versus seed receiving the base treatment $(\mathrm{RF}=4.4)$. Additionally, ILeVO $(\mathrm{RF}=1.7)$ reduced $\mathrm{SCN}$ reproduction by more than one-and-a-half fold compared with the base treatment $(\mathrm{RF}=3.2)$ in the 2017 West Central experiment. When pooled by region (Table 4 ), there was a significant reduction in SCN reproduction observed across the experiments in the Central region in 2017, where the RF in plots with the ILeVO treatment was 1.4 and RF was 2.3 in the plots with only the base seed treatment. Though SCN reproduction was reduced in the ILeVO treatments in the experiments in the Central region, no RF was less than 1, meaning that $\mathrm{SCN}$ population densities increased over the season in both treatments at these experimental locations.

There were two small-plot experiments in which the ILeVO treatment had an $\mathrm{RF}<1.0$, indicating that $\mathrm{SCN}$ numbers decreased during the season, and the base treatment had an RF $>1.0$, indicating that SCN numbers increased (Table 2). In the experiment in Southcentral Iowa in 2016, there was an almost 50\% decrease in SCN reproduction observed with ILeVO $(\mathrm{RF}=0.6)$ versus the base treatment $(\mathrm{RF}=1.5)$. Also, in the experiment in Central Iowa in 2017, a half-fold reduction in SCN reproduction occurred in the treatment with ILeVO $(\mathrm{RF}=0.9)$ as compared with the base treatment $(\mathrm{RF}=$ 1.4). In addition, $\mathrm{SCN}$ reproduction was significantly reduced in the ILeVO-treated strips $(\mathrm{RF}=0.3)$ as compared with the basetreated strips $(\mathrm{RF}=0.7)$ at the Webster County location in 2015 , although SCN numbers decreased throughout the season in both treatments (Table 3).

Also, there was a significant season-long increase in SCN population densities associated with the ILeVO treatment compared with the base in one small-plot experiment, at the Southcentral location in 2017 (Table 2). A fivefold increase in SCN RF occurred in the ILeVO-treated plots $(\mathrm{RF}=9.3)$ compared with the plots with the base seed treatment $(\mathrm{RF}=4.3)$. No significant differences between treatments were observed for RF at any other location or over all years in any other region (Table 4), nor were there significant differences observed between treatments at any of the other strip-trial experiments (Table 3).

Effects of ILeVO on soybean yield. Significant increases in soybean yield were observed in the ILeVO treatment compared with the

Table 3. Mean reproduction of Heterodera glycines and mean soybean yield in the strip-trial experiments for strips treated with and without ILeVO and the difference between treatment means for each location in each year ${ }^{\mathrm{a}}$

\begin{tabular}{|c|c|c|c|c|c|c|c|}
\hline \multirow[b]{2}{*}{ Year, county } & \multirow[b]{2}{*}{ Cultivar } & \multicolumn{3}{|c|}{ SCN reproductive factor ${ }^{b}$} & \multicolumn{3}{|c|}{ Yield (bushels/acre) } \\
\hline & & ILeVO + base & Base & Difference $^{\mathrm{c}}$ & ILeVO + base & Base & Difference $^{c}$ \\
\hline \multicolumn{8}{|l|}{2015} \\
\hline Bremer & AG2031 & 1.1 & 1.2 & -0.1 & 74.8 & 75.1 & -0.3 \\
\hline Chickasaw 1 & AG2031 & 2.0 & 3.9 & -1.9 & 55.0 & 54.8 & 0.2 \\
\hline Chickasaw 2 & AG2031 & 1.7 & 3.8 & -2.1 & $\ldots$ & $\ldots$ & $\ldots$ \\
\hline Clay & AG2031 & 1.3 & 1.4 & -0.1 & 69.0 & 66.6 & 2.4 \\
\hline Webster & AG2031 & 0.3 & 0.7 & $-0.4 *$ & 64.3 & 63.7 & 0.6 \\
\hline \multicolumn{8}{|l|}{2016} \\
\hline Bremer & AG2031 & 0.9 & 1.0 & -0.1 & 80.7 & 79.9 & 0.8 \\
\hline Clay & AG2031 & 1.2 & 0.7 & 0.5 & 78.7 & 78.6 & 0.1 \\
\hline Humboldt $^{\mathrm{d}}$ & AG2031 & 8.6 & 8.4 & 0.2 & 58.0 & 59.6 & $-1.6^{*}$ \\
\hline Jasper & AG3231 & 0.9 & 1.0 & -0.1 & 68.2 & 68.6 & -0.4 \\
\hline Johnson $^{\mathrm{d}}$ & AG3231 & 1.4 & 1.2 & 0.2 & 43.0 & 40.3 & $2.7 * *$ \\
\hline Story & AG2031 & 3.1 & 2.3 & 0.8 & 68.1 & 66.3 & 1.8 \\
\hline Warren & AG3231 & $\ldots$ & $\ldots$ & $\ldots$ & 56.7 & 54.8 & $1.9^{*}$ \\
\hline \multicolumn{8}{|l|}{ All } \\
\hline Locations in 2015 & $\ldots$ & 1.3 & 2.1 & -0.8 & 65.8 & 65.1 & 0.7 \\
\hline Locations in $2016^{\mathrm{d}}$ & $\ldots$ & 1.6 & 1.3 & 0.3 & 69.7 & 70.5 & 0.8 \\
\hline Years $^{\mathrm{d}}$ & $\cdots$ & 1.4 & 1.8 & -0.4 & 68.4 & 67.6 & $0.8^{*}$ \\
\hline
\end{tabular}

${ }^{a}$ Statistical differences are reported and significance was determined at $P=0.10$. Data from all locations were pooled by year and over all years.

${ }^{b}$ Reproductive factor was calculated by dividing the number of soybean cyst nematode $(\mathrm{SCN})$ eggs at each sampling point at harvest $\left(\mathrm{P}_{\mathrm{f}}\right)$ by the number at each sampling point at planting $\left(\mathrm{P}_{\mathrm{i}}\right)$.

${ }^{c}$ Difference was calculated by subtracting the mean SCN reproductive factor or mean yield for the Poncho/VOTiVO + Acceleron F treatment (base) from the Poncho/VOTiVO + Acceleron F + ILeVO treatment (ILeVO + base). Asterisks * and ** indicate that the difference between treatments was statistically significant at $P \leq 0.10$ and $P \leq 0.001$, respectively.

d These two on-farm experiments had sudden death syndrome disease index values $>10$ and, therefore, yields from these experiments were not used in the overall analyses for 2016 and across 2 years. 
base treatment in multiple small-plot and strip-trial experiments (Table 2). In 2016 , a significant yield increase $(P=0.002)$ of 3.7 bushels/acre (bu/ac) $(249 \mathrm{~kg} / \mathrm{ha})$ occurred in the experiment at the Northwest location in the plots grown from seed treated with ILeVO $(83.4 \mathrm{bu} / \mathrm{ac} ; 5,609 \mathrm{~kg} / \mathrm{ha})$ versus the base treatment $(79.7 \mathrm{bu} / \mathrm{ac}$; $5,360 \mathrm{~kg} / \mathrm{ha}$ ). And, in 2017, a significant yield increase occurred with the ILeVO treatment in two small-plot experiments. In the experiment at the Southcentral location $(P=0.03)$, the ILeVO treatment averaged $60 \mathrm{bu} / \mathrm{ac}(4,035 \mathrm{~kg} / \mathrm{ha})$, which was $2.9 \mathrm{bu} / \mathrm{ac}(195 \mathrm{~kg} / \mathrm{ha})$ more than the base treatment. Similar results were obtained in the experiment at the Southeast location, where plots grown from ILeVOtreated seed averaged $73.2 \mathrm{bu} / \mathrm{ac}(4,923 \mathrm{~kg} / \mathrm{ha})$, which was 2.8 $\mathrm{bu} / \mathrm{ac}(188 \mathrm{~kg} / \mathrm{ha})$ greater than the base treatment alone. There were no other significant increases or decreases in yield in the plots with ILeVO versus the base treatment in any other small-plot experiment. When the data from individual small-plot experiments were combined by region, a significant $(P=0.03)$ yield increase of $2.5 \mathrm{bu} / \mathrm{ac}$ (168 kg/ha) was detected in 2016 with ILeVO (80.6 bu/ac; $5,420 \mathrm{~kg} / \mathrm{ha})$ versus the base treatment $(78.1 \mathrm{bu} / \mathrm{ac} ; 5,252 \mathrm{~kg} / \mathrm{ha})$ among the experiments in the Northern region (Table 4). And, when all locations in the Northern region were pooled over all years, a significant $(P=0.06)$ yield increase of $0.9 \mathrm{bu} / \mathrm{ac}(60.5 \mathrm{~kg} / \mathrm{ha})$ was detected in the ILeVO-treated plots $(70.8 \mathrm{bu} / \mathrm{ac} ; 4,761 \mathrm{~kg} / \mathrm{ha})$ compared with the base seed treatment (69.9 bu/ac; 4,701 kg/ha). No significant differences between treatments were detected in any other region, location, or year whether the data were analyzed by location or were pooled across locations or years.

In the 2 years of strip trials, a significant difference between treatments $(P<0.10)$ was observed only at the Warren County location in 2016 (Table 3 ). A yield increase of $1.9 \mathrm{bu} / \mathrm{ac}(130 \mathrm{~kg} / \mathrm{ha})$ occurred in the treatment with ILeVO (56.7 bu/ac; $3,813 \mathrm{~kg} / \mathrm{ha})$ compared with the base treatment $(54.8 \mathrm{bu} / \mathrm{ac} ; 3,685 \mathrm{~kg} / \mathrm{ha})$. When the yield data were pooled over all locations of the strip-trial experiments for both years, a significant yield increase of $0.8 \mathrm{bu} / \mathrm{ac}(54 \mathrm{~kg} / \mathrm{ha})$ was detected in the ILeVO-treated strips ( $68.4 \mathrm{bu} / \mathrm{ac} ; 4,600 \mathrm{~kg} / \mathrm{ha})$ versus those with only the base treatment ( $67.6 \mathrm{bu} / \mathrm{ac} ; 4,546 \mathrm{~kg} / \mathrm{ha})$. Significant differences between treatments were not observed at any other location or when locations were pooled by year.
For strip-trial experiments, the treatment differences due to ILeVO within each location and across 2 years were expressed as $90 \%$ confidence intervals for percent yield change (Fig. 2). Confidence intervals in 8 of the 10 locations included zero yield change, providing no evidence of a significant effect of ILeVO on yield. Although the average percent yield change for 8 of the 10 trial locations represented a numerical yield increase with the addition of ILeVO, only 1 strip trial was a significant, positive yield difference. The overall effect of ILeVO across all 10 trials in 2 years was a little more than $1.0 \%$ and ranged from -1.1 to $4.6 \%$ yield response.

\section{Discussion}

The effects of ILeVO on SCN RF and soybean yield across numerous environments and over multiple years in these experiments were variable. At times, significant reductions in SCN reproduction were observed but corresponding significant increases in soybean yield did not occur in those experiments. Conversely, there were significant increases in soybean yields associated with ILeVO in several small-plot experiments but significant decreases in SCN RF were not detected in those studies. Our results with ILeVO are somewhat different than results of previous research on other nematodeprotectant seed treatments conducted by Gaspar et al. (2014), Mourtzinis et al. (2017), and Bissonnette et al. (2018), all of whom found that the addition of a nematicide or nematode protectant to a fungicide plus insecticide seed treatment base did not significantly increase yield in a single site-year of a small-plot experiment. However, a reduction in $\mathrm{SCN}$ reproduction was detected in some experiments.

The reason for the lack of consistent effects on yield and SCN reproduction by treatments applied in our experiments may be attributed to a number of factors, including the SCN population density in the soil (Beeman and Tylka 2018), spatial variability of SCN within each field (Avendaño et al. 2004), and soil edaphic factors (soil physical structure, water holding capacity, $\mathrm{pH}$, temperature, and so on) (Stirling 2014). For example, a greenhouse study conducted by Beeman and Tylka (2018) found that, at higher SCN population densities $\left(4,000 \mathrm{SCN}\right.$ eggs per $100 \mathrm{~cm}^{3}$ of soil or greater), the number of females per gram of root on a resistant cultivar did not

Table 4. Mean reproduction of Heterodera glycines and mean soybean yield by region in the small-plot experiments for plots treated with and without ILeVO and the difference between treatment means for each region in each year and pooled over all years ${ }^{\mathrm{a}}$

\begin{tabular}{|c|c|c|c|c|c|c|}
\hline \multirow[b]{2}{*}{ Year, region ${ }^{b}$} & \multicolumn{3}{|c|}{ SCN reproductive factor ${ }^{c}$} & \multicolumn{3}{|c|}{ Yield (bushels/acre) } \\
\hline & ILeVO + base & Base & Difference $^{\mathrm{d}}$ & ILeVO + base & Base & Difference $^{d}$ \\
\hline \multicolumn{7}{|l|}{2015} \\
\hline Northern & 1.3 & 1.7 & 0.1 & 68.8 & 68.7 & 0.1 \\
\hline Central & 1.4 & 2.1 & -0.7 & 70.7 & 70.1 & 0.6 \\
\hline Southern ${ }^{\mathrm{e}}$ & 2.3 & 1.9 & 0.4 & 58.4 & 58.7 & -0.3 \\
\hline \multicolumn{7}{|l|}{2016} \\
\hline Northern & 6.1 & 9.1 & -3.0 & 80.6 & 78.1 & $2.5^{*}$ \\
\hline Central & 7.5 & 5.8 & 1.7 & 75.0 & 75.1 & -0.1 \\
\hline Southern & 1.0 & 1.3 & -0.3 & 64.9 & 65.8 & -0.9 \\
\hline \multicolumn{7}{|l|}{2017} \\
\hline Northern & 11.9 & 13.1 & -1.2 & 63.0 & 63.0 & 0.0 \\
\hline Central & 1.4 & 2.3 & $-0.9^{*}$ & 76.2 & 76.5 & -0.3 \\
\hline Southern & 23.0 & 23.4 & -0.4 & 69.8 & 68.0 & 1.8 \\
\hline \multicolumn{7}{|l|}{ All years } \\
\hline Northern & 7.3 & 9.0 & -1.7 & 70.8 & 69.9 & $0.9 *$ \\
\hline Central & 3.4 & 3.4 & 0.0 & 74.0 & 73.9 & 0.1 \\
\hline Southern ${ }^{\mathrm{e}}$ & 9.6 & 9.7 & -0.1 & 65.0 & 65.0 & 0.0 \\
\hline
\end{tabular}

${ }^{a}$ Statistical differences are reported and significance was determined at $P=0.10$.

${ }^{b}$ Region represents a grouping of three experimental locations of the small-plot trials in the Northern (Northwest, Northcentral, and Northeast), Central (West Central, Central, and East Central), and Southern (Southwest, Southcentral, and Southeast) portions of the state of Iowa.

${ }^{c}$ Reproductive factor was calculated by dividing the number of soybean cyst nematode $(\mathrm{SCN})$ eggs in each plot at harvest $\left(\mathrm{P}_{\mathrm{f}}\right)$ by the number in each plot at planting $\left(\mathrm{P}_{\mathrm{i}}\right)$.

${ }^{d}$ Difference was calculated by subtracting the mean SCN reproductive factor or mean yield for the Poncho/VOTiVO + Acceleron F treatment (base) from the Poncho/VOTiVO + Acceleron F + ILeVO treatment (ILeVO + base). Asterisks $(*)$ indicate that the difference between treatments was statistically significant $(P \leq 0.10)$.

e Sudden death syndrome disease index values were $>10$ at the Southcentral experiment in 2015. Consequently, yield and reproductive factor data from this location were removed from analyses. 
significantly differ between seed treated with fluopyram alone (no base) versus untreated seed. At lower population densities $(1,000$ SCN eggs per $100 \mathrm{~cm}^{3}$ of soil or less), the number of females per gram of root was significantly lower in the fluopyram-treated seed as compared with the nontreated control. All four of the small-plot experiments in which significant reductions in SCN RF were detected with ILeVO were in fields with initial SCN population densities of less than 1,850 eggs per $100 \mathrm{~cm}^{3}$ of soil. However, 18 of the 27 small-plot experiments had initial SCN population densities of less than 2,000 eggs per $100 \mathrm{~cm}^{3}$ of soil, and no significant effect of ILeVO on SCN RF was detected in 14 of those 18 experiments. These results suggest that the use of ILeVO in fields with a low initial SCN population density may not result in significant reductions in SCN reproduction.

There was a significant increase in $\mathrm{SCN}$ reproduction in the ILeVO-treated plots as compared with the plots using the base seed treatment in a single small-plot experiment in 2017. In the ILeVOtreated plots, the final density of SCN eggs in the soil was more than nine times greater than the initial SCN egg density. We have no plausible explanation for the increase, and no other published studies have reported increases in SCN reproduction associated with use of a nematode-protectant seed treatment.

The lack of comprehensive understanding of the relationship between SDS and SCN (Hirrel 1987; Melgar et al. 1994; Roy et al. 2000; Westphal et al. 2014; Xing and Westphal 2006) confounds efforts to study and understand how seed treatments affect each individual pathogen and disease and the associated yield responses when both diseases are present. To properly evaluate the effects of ILeVO on SCN reproduction and its relationship to yield independently of SDS, the plants in the experiments should have an SDS foliar disease index below 10 (Kandel et al. 2016b). Consequently, we only used the data from small-plot and strip-trial experiments in which the SDS disease index value was less than 10 to increase the likelihood that the yield differences detected in our experiments would be associated with effects of ILeVO on SCN rather than be associated with SDS control. Nonetheless, we cannot be certain that the effects of ILeVO on yield in our experiments were partially or solely due to effects on SCN, particularly because we did not dig plants to look for possible root symptoms of SDS.

In the 26 site-years of data from small-plot experiments and 10 site-years of data from strip-trial experiments, the plots grown from seed treated with ILeVO reduced SCN reproduction significantly in 5 individual experiments and increased yield significantly in 4 separate experiments. Kandel et al. (2017) reported the results of 12 small-plot field experiments conducted across Illinois, Indiana, Iowa, Michigan, and Ontario, Canada, from 2014 to 2015. Overall, ILeVO significantly increased soybean yields in their studies and had no effect on SCN population densities or RF values. The six experiments they conducted in 2014 had an overall average SDS disease index value of less than 10, whereas the average SDS disease index value in the six experiments in 2015 was 12.75 . The results from their experiments were not reported individually; thus, it is not known whether the SDS disease index value in any individual experiment was less than 10, whether significant yield increases or reductions in SCN reproduction occurred in individual experiments, or how effects of the seed treatments on yield may have related to SDS disease index in individual experiments. Work by Roth et al. (2020) also studied the effects of fluopyram on SCN reproduction but at a single site in Michigan with natural infestation of both SCN and SDS. Much like the work by Kandel et al. (2016a), SDS index values were greater than 10 in multiple years, especially for varieties with the PI 88788 source of resistance. Additionally, significant differences were reported each year among cultivars for yield, SCN reproduction, final SCN populations, and SDS index. For this reason, the effects of ILeVO reported by Kandel et al. (2017) and Roth et al. (2020) relating to SCN reductions are likely confounded by the interaction between SCN and the SDS pathogen.

The small-plot and the strip-trial experiments we conducted were on very different spatial scales. The experimental units in the small- plot experiments were plots that were $10 \mathrm{ft}(3.0 \mathrm{~m})$ wide by $17 \mathrm{ft}$ $(5.15 \mathrm{~m})$ long whereas the experimental units in the strip trials were $20 \mathrm{ft}(6.1 \mathrm{~m})$ or more wide, depending on the cooperating farmer's equipment, by $820 \mathrm{ft}(250 \mathrm{~m})$ to $1,600 \mathrm{ft}(488 \mathrm{~m})$ long. Nonetheless, it is reasonable to compare the results of the strip trials and small-plot experiments because the exact same treated seed were used in both types of experiments. Results of the two types of experiments were similarly variable, and the conclusions from both types of experiments were essentially the same.

Bissonnette et al. (2018) used the same seed in small-plot and strip-trial experiments such as those reported herein to study the effects of Clariva Complete Beans on soybean yields and seasonlong reproduction of SCN. Their results varied more between the small-plot and strip-trial experiments than our results with ILeVO. Specifically, a significant reduction in SCN RF occurred with Clariva Complete Beans in 2 of 27 site-years of small-plot experiments but no such reduction in SCN RF was detected in any of the 18 strip trials with the same treatment. Also, Clariva Complete Beans increased yields in 5 of 18 strip trials but there was no significant difference in yields between Clariva Complete Beans and its base in any of the small-plot experiments. The differences in results between strip-trial and small-plot experiments with Clariva Complete Beans and ILeVO could possibly be due to differences in the activity of the two seed treatments on the biology of SCN.

The basis of the variable yield and SCN reproduction results with ILeVO seed treatment among our experiments is not readily apparent or known. There was no obvious pattern in the results based on year, initial or final SCN population density, HG type of the SCN population, yield level, or cultivar. McCarville et al. (2017) found that increases in SCN population densities in numerous field experiments across Iowa were positively correlated with soil temperature and negatively correlated with soil moisture. Perhaps the effects of ILeVO and possibly other nematode-protectant seed treatments are similarly affected by soil temperature and moisture levels during the growing season. We did not test for correlations among soil temperature and moisture, yield responses, and SCN results among the locations of the experiments. There are many other edaphic factors, including soil microbes, that also may have affected yield responses and RF values.

With the effectiveness of SCN-resistant cultivars diminishing (McCarville et al. 2017), nematode-protectant seed treatments are a much-needed new management tactic for integrated management of this very important soybean pest. ILeVO decreased SCN reproduction and increased soybean yield in some of our field experiments but the effects were not consistent or predictable. More work is needed to understand why results are variable and how soil ecological factors and SCN population densities influence the effectiveness of nematode-protectant seed treatments for SCN.

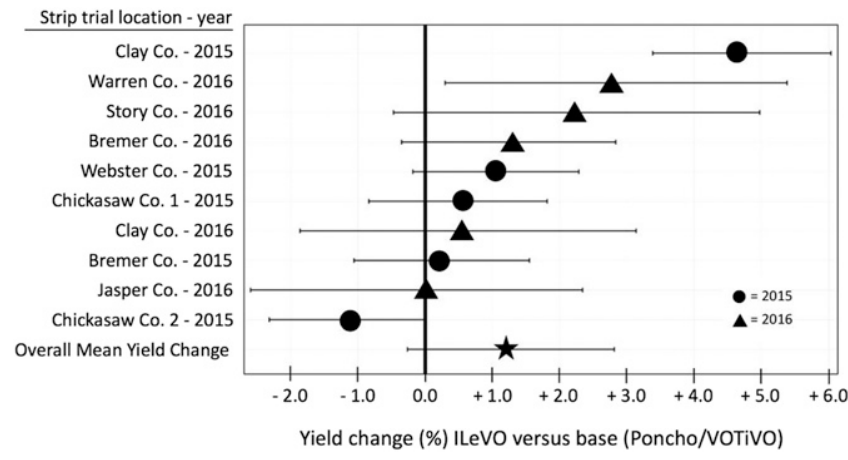

Fig. 2. Mean yield difference between replicated strips grown from seed treated with ILeVO compared with the base fungicide and insecticide. Change values are arranged in order from largest positive value to largest negative value. Horizontal lines through each symbol indicate $90 \%$ confidence intervals for the mean yield change. Yield change is significantly different from zero if the $90 \%$ interval does not include zero. 


\section{Acknowledgments}

We thank the farmer cooperators for their assistance in the establishment, maintenance, and execution of the strip trials; M. Serrano for processing soil samples from the strip-trial experiments to determine SCN population densities; Bayer Crop Science for providing the seed and seed treatments for the studies and for their financial support of the Iowa Soybean Association On-Farm Network strip-trial experiments; and the numerous field staff and laboratory assistants from Iowa State University and the Iowa Soybean Association who worked to collect, process, and count each soil sample.

\section{Literature Cited}

Allen, T. W., Bradley, C. A., Sisson, A. J., Byamukama, E., Chilvers, M. I., Coker, C. M., Collins, A. A., Damicone, J. P., Dorrance, A. E., Dufault, N. S., Esker, P. D., Faske, T. R., Giesler, L. J., Grybauskas, A. P., Hershman, D. E., Hollier, C. A., Isakeit, T., Jardine, D. J., Kelly, H. M., Kemerait, R. C., Kleczewski, N. M., Koenning, S. R., Kurle, J. E., Malvick, D. K., Markell, S. G., Mehl, H. L., Mueller, D. S., Mueller, J. D., Mulrooney, R. P., Nelson, B. D., Newman, M. A., Osborne, L., Overstreet, C., Padgett, G. B., Phipps, P. M., Price, P. P., Sikora, E. J., Smith, D. L., Spurlock, T. N., Tande, C. A., Tenuta, A. U., Wise, K. A., and Wrather, J. A. 2017. Soybean yield loss estimates due to diseases in the United States and Ontario, Canada from 2010 to 2014. Plant Health Prog. 18:19-27.

Avendaño, F., Pierce, F. J., Schabenberger, O., and Melakeberhan, H. 2004. The spatial distribution of soybean cyst nematode in relation to soil texture and soil map unit. Agron. J. 96:181-194.

Beeman, A. Q., Njus, Z. L., Pandey, S., and Tylka, G. L. 2019. The effects of ILeVO and VOTiVO on root penetration and behavior of the soybean cyst nematode, Heterodera glycines. Plant Dis. 103:392-397.

Beeman, A. Q., and Tylka, G. L. 2018. Assessing the effects of ILeVO and VOTiVO seed treatments on reproduction, hatching, motility, and root penetration of the soybean cyst nematode, Heterodera glycines. Plant Dis. 102:107-113.

Bissonnette, K. M., Marett, C. C., Mullaney, M. P., Gebhart, G. D., Kyveryga, P., Mueller, T. A., and Tylka, G. L. 2018. Effects of Clariva Complete Beans seed treatment on Heterodera glycines reproduction and soybean yield in Iowa. Plant Health Prog. 19:1-8.

Faghihi, J., and Ferris, J. M. 2000. An efficient new device to release eggs from Heterodera glycines. J. Nematol. 32:411-413.

Faske, T. R., and Hurd, K. 2015. Sensitivity of Meloidogyne incognita and Rotylenchulus reniformis to fluopyram. J. Nematol. 47:316-321.

Gaspar, A. P., Marburger, D. A., Mourtzinis, S., and Conley, S. P. 2014. Soybean yield response to multiple seed treatment components across diverse environments. Agron. J. 106:1955-1962.

Gerdemann, J. W. 1955. Relation of a large soil-borne spore to phycomycetous mycorrhizal infections. Mycologia 47:619-632.

Hadfield, J. D. 2010. MCMC methods for multi-response generalized linear mixed models: The MCMCglmm $R$ Package. J. Stat. Softw. 33.

Hirrel, M. C. 1987. Sudden death syndrome of soybean: New insights into its development. Pages 95-104 in: Am. Seed Trade Assoc. 16th Soybean Res. Conf.

Jackson, C. S., Faske, T. R., and Kirkpatrick, T. L. 2015. Assessment of ILeVO® for Management of Meloidogyne incognita on Soybean. Page 77 in: Arkansas Soybean Research Studies 2015. J. Ross, ed. Arkansas Agricultural Experiment Station, Fayetteville, AR.

Jones, J. G., Kleczewski, N. M., Desaeger, J., Meyer, S. L. F., and Johnson, G. C. 2017. Evaluation of nematicides for southern root-knot nematode management in lima bean. Crop Prot. 96:151-157.

Kandel, Y. R., Wise, K. A., Bradley, C. A., Chilvers, M. I., Byrne, A. M., Tenuta, A. U., Faghihi, J., Wiggs, S. N., and Mueller, D. S. 2017. Effect of soybean cyst nematode resistance source and seed treatment on population densities of
Heterodera glycines, sudden death syndrome, and yield of soybean. Plant Dis. 101:2137-2143.

Kandel, Y. R., Wise, K. A., Bradley, C. A., Chilvers, M. I., Tenuta, A. U., and Mueller, D. S. 2016a. Fungicide and cultivar effects on sudden death syndrome and yield of soybean. Plant Dis. 100:1339-1350.

Kandel, Y. R., Wise, K. A., Bradley, C. A., Tenuta, A. U., and Mueller, D. S. 2016b. Effect of planting date, seed treatment, and cultivar on plant population, sudden death syndrome, and yield of soybean. Plant Dis. 100: $1735-1743$.

Laurent, A., Kyveryga, P., Makowski, D., and Miguez, F. 2019. A framework for visualization and analysis of agronomic field trials from on-farm research networks. Agron. J. 111:2712-2723.

McCarville, M. T., Marett, C. C., Mullaney, M. P., Gebhart, G. D., and Tylka, G. L. 2017. Increase in soybean cyst nematode virulence and reproduction on resistant soybean varieties in Iowa from 2001 to 2015 and the effects on soybean yields. Plant Health Prog. 18:146-155.

McLean, K. S., and Lawrence, G. W. 1993. Interrelationship of Heterodera glycines and Fusarium solani in sudden death syndrome of soybean. J. Nematol. 25:434-439.

Melgar, J., Roy, K. W., and Abney, T. S. 1994. Sudden death syndrome of soybean: Etiology, symptomology, and effects of irrigation and Heterodera glycines on incidence and severity under field conditions. Can. J. Bot. 72: $1647-1653$.

Mourtzinis, S., Marburger, D., Gaska, J., Diallo, T., Lauer, J., and Conley, S. 2017. Corn and soybean yield response to tillage, rotation, and nematicide seed treatment. Crop Sci. 57:1704-1712.

Niblack, T. L., Arelli, P. R., Noel, G. R., Opperman, C. H., Orf, J. H., Schmitt, D. P., Shannon, J. G., and Tylka, G. L. 2002. A revised classification scheme for genetically diverse populations of Heterodera glycines. J. Nematol. 34: 279-288.

Niblack, T. L., Heinz, R. D., Smith, G. S., and Donald, P. A. 1993. Distribution, density, and diversity of Heterodera glycines in Missouri. J. Nematol. 25: 880-886.

Njiti, V. N., Shenaut, M. A., Suttner, R. J., Schmidt, M. E., and Gibson, P. T. 1998. Relationship between soybean sudden death syndrome disease measures and yield components in F6-derived lines. Crop Sci. 38:673-678.

Roth, M. G., Jacobs, J. L., Napieralski, S., Byrne, A. M., Stouffer-Hopkins, A., Warner, F., and Chilvers, M. I. 2020. Fluopyram suppresses population densities of Heterodera glycines in field and greenhouse studies in Michigan. Plant Dis. 104:1305-1311.

Roy, K. W., Patel, M. V., and Baird, R. E. 2000. Colonization of Heterodera glycines cysts by Fusarium solani form A, the cause of sudden death syndrome, and other fusaria in soybean field in the Midwestern and southern United States. Phytoprotection 81:49-94.

RStudio Team. 2015. RStudio: Integrated Development Environment for R. RStudio, Inc., Boston, MA, U.S.A.

Stirling, G. R. 2014. The soil food web and the soil nematode community. Pages 48-76 in: Biological Control of Plant-Parasitic Nematodes. CAB International, London, U.K.

Tylka, G. L., and Marett, C. C. 2017. Known distribution of the soybean cyst nematode, Heterodera glycines, in the United States and Canada, 1954 to 2017. Plant Health Prog. 18:167-168.

Westphal, A., Li, C., Xing, L., McKay, A., and Malvick, D. 2014. Contributions of Fusarium virguliforme and Heterodera glycines to the disease complex of sudden death syndrome of soybean. PLoS One 9:e99529.

Xing, L., and Westphal, A. 2006. Interaction of Fusarium solani f. sp. glycines and Heterodera glycines in sudden death syndrome of soybean. Phytopathology 96:763-770. 